\title{
Distance Communication of the Lecturer and Students in the Higher Education
}

\author{
Roman Yavich $^{1} \&$ Alexandra Gerkerova ${ }^{2}$ \\ ${ }^{1}$ Ariel University, Ariel, Israel \\ 2 South Ukrainian National Pedagogical University named after K. D. Ushynsky, Ukraine \\ Correspondence: Roman Yavich, Ariel University, Ariel, Israel. E-mail: romany@ariel.ac.il
}

Received: March 5, 2019

Accepted: April 15, 2019

Online Published: April 17, 2019

doi:10.5430/ijhe.v8n2p82

URL: https://doi.org/10.5430/ijhe.v8n2p82

\begin{abstract}
The article suggests an information-pedagogical model of a teacher-student interaction via telecommunication means. The necessity of information technologies implementation into the educational process is determined by the changing role of the teacher in today's education. The suggested model may help to develop the theoretical grounds for comprehensive management of students' educational activity distantly, the model may be also used for the work with the students who take full-time course.
\end{abstract}

Keywords: educational process, distant communication, students' individual work organization

\section{Introduction}

Nowadays the problems of distant (open) education are widely discussed. The following advantages of the information and distant technologies use in the educational process have been identified in the works of the researchers (Ahayan, year; Hen, 1996; Ibragimov 2005; Mioduser, Nachmias, Lahov, \& Oren, 1999; Nachmias \& Segev, 2003; Offir, Lev, Barth, \& Shteinbok, 2004):

- new ways of the students' individual work organization;

- increased intensity of the educational process;

- additional motivation for educational activity;

- availability of educational materials at any time;

- opportunity for self-assessment of the progress made.

The necessity of information technologies implementation into the educational process is determined by the changing role of the teacher in today's education: the main goal is not to provide students with information but to teach them how to work with it. Now the role of a teacher lies in the field of planning and management of students' educational activities. Modern Internet technologies provide the students with a wide and ready access to the educational information resources. A student can individually master a subject in an interactive way, to communicate and participate in discussions on studied problems, to get support and consultation from the teacher.

Telecommunication technologies make it possible to actively communicate with students, to manage their educational activity, which should have such characteristics as completeness, continuity in time, convenience and efficiency (Hen, 1996; Malanin, Suslonov, \& Polyann, 2001; Starichenko, Davidovich, Yavich, \& Mahrova, 2007). At the same time, in most cases a teacher-student interaction is realized only through a dialogue in the classroom and is usually initialized by the teacher. Hence, communication is incidental, having nothing to do with the constant management of the students' educational activity. Distant communication, as a rule, is used only with the students who take distant or part-time courses (Domoshnitsky \& Yavich, 2009; Davidovich \& Yavich, 2013), but, in our opinion, development of the distant student-teacher interaction has become urgent.

\subsection{Development of Telecommunication Interaction}

Development of telecommunication interaction covers the following stages:

- revision of the available network communication means; 
- identification of the didactic potential of various communication means and conditions of their effective application in the educational process;

- development of the pedagogical model of various communication means application

The first two stages were described by the authors in the previous article (Starichenko, Egorov, \& Yavich, 2013). In the present publication we suggest an information-pedagogical model of a student-teacher interaction via telecommunication means.

We will define pedagogical network communication means as follows: computer network services that provide distant access to the educational resources and effective teacher-student communication.

It is necessary to make two comments regarding this definition.

First, two primary functions that are carried out by means of distant technologies are specified in the definition: a distant access to the network educational resources and the teacher-student distant interaction.

Secondly, communication is considered effective if it is carried out promptly and solves certain problems, but in case of student-teacher interaction necessity and forms of communication are determined each time individually. So, the teacher should

1) prepare the information resources and make them accessible by means of telecommunications;

2) develop the model of distant interaction

According to the number of people participating in the conversation pedagogical network communication technologies are subdivided into:

- "to-one" $([\rightarrow 1])$ - the unidirectional channel of information transfer from a source (resource) to the consumer;

- $\quad$ "one-to-all" $([1 \rightarrow \mathrm{n}])$ - simultaneous information transfer from one source to many consumers on the unidirectional channel (announcement);

- "one-with-one" $([1 \leftrightarrow 1])$ - personal bidirectional dialogue;

- "all-with-one" $([\mathrm{n} \leftrightarrow 1])$ - bidirectional conversation of many participants with one;

- "all-with-all” ([n↔n]) - bidirectional conversation between all participants.

"To-one" type of communication concerns resource communications - the user gets access to the provided information resources. "One-to-all" type of communication is unilateral transmission of the information from one (allocated) source to many users. Three remaining types ("one-with-one", "all-with-one", and "all-with-all") are bidirectional communication means - they differ in number of intercourse participants. Development of the information-pedagogical model of distant communication demands formulation of the general principles reflecting pedagogical and technological aspects of communication.

\subsection{Principles}

Research of the literature on the subject and our experience in distant education implementation makes it possible to establish the following principles:

- didactic conditionality of communication - student-teacher communication is not self-sufficient, it is required only in particular didactic situations and should not limit students' individual educational activity, but give the teacher an opportunity to effectively manage the students' educational activity.

- accuracy and integrity of information - educational information resources should provide the student with the possibility to study the subject on different levels of complexity, beginning with the level of curriculum requirements;

- technological urgency - orientation to modern means and methods of organization and storage of information, access to it, and also varieties of ways and means of communication;

- openness - the possibility to introduce new information sources and communication means into the educational process should be provided;

- adaptability - practical realization of distant management should provide adaptation to conditions of the educational process of a concrete educational institution; 
- minimization of the teacher's tasks - preference is given to the management methods, focusing on the students' individual activity; open access to the necessary information and its interpretation, self-testing materials, opportunity to communicate with the other students.

These principles allow us to construct the information-pedagogical model of distant communication.

The components of the information models are sources and receivers (consumers) of the information, information resources; thus communications between the components are carried out in the form of information streams.

The functions of the modeled information system, meeting the needs of its users, are: collection and registration of information resources, their storage, processing, actualization, and also processing of users' inquiries (Bukhanceva, 2007; Prozorov, 2003). Classification of educational information resources that can be used by students in the process of individual educational activity, according to the character of access and use is presented in Figure 1.

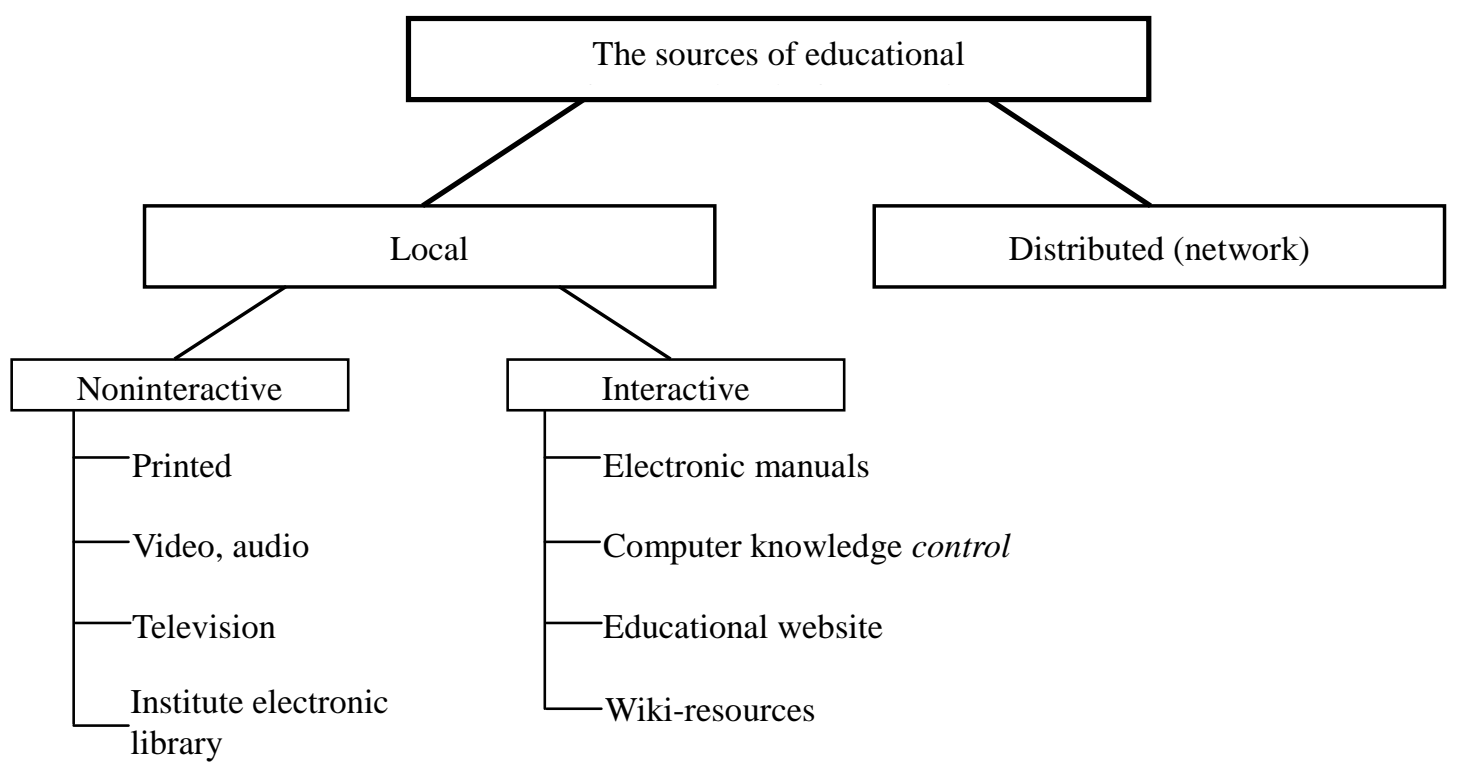

Figure 1. The sources of educational

\section{Classification of Information Educational Resources}

Sources are divided into local and distributed since local are the property of the educational institution stored in information repositories - paper and electronic libraries and websites. Unlike them, distributed sources do not belong to the concrete institution and are available on various Internet sites and portals. Non-interactive sources provide only unidirectional information transfer (from storage to the consumer, i.e., the student); the consumer cannot change the content or an order of the material representation. Interactive sources provide the consumer with the possibility of information interaction that makes it possible to individualize the educational process, realize active forms of training (for example, research computer modeling), automation of learning results monitoring. The example of such sources, that have started to play an important role in nowadays education, is wiki-resources. They can be easily created and developed by students (wiki is a name of the technology of a website or a database collaborative creation by a community of users, where each student can add or edit content. The example of such a website is free encyclopedia "Wikipedia" (e.g., http://ru.wikipedia.org/wiki/). Development and use of such resources has a considerable didactic potential as it is based on voluntary and independent participation of student-developers. On the other hand, such participation makes sense only if the developer has sufficiently mastered the material (that, finally, is the training purpose).The model of the participants' of the educational process distant communication is presented in Figure2. 


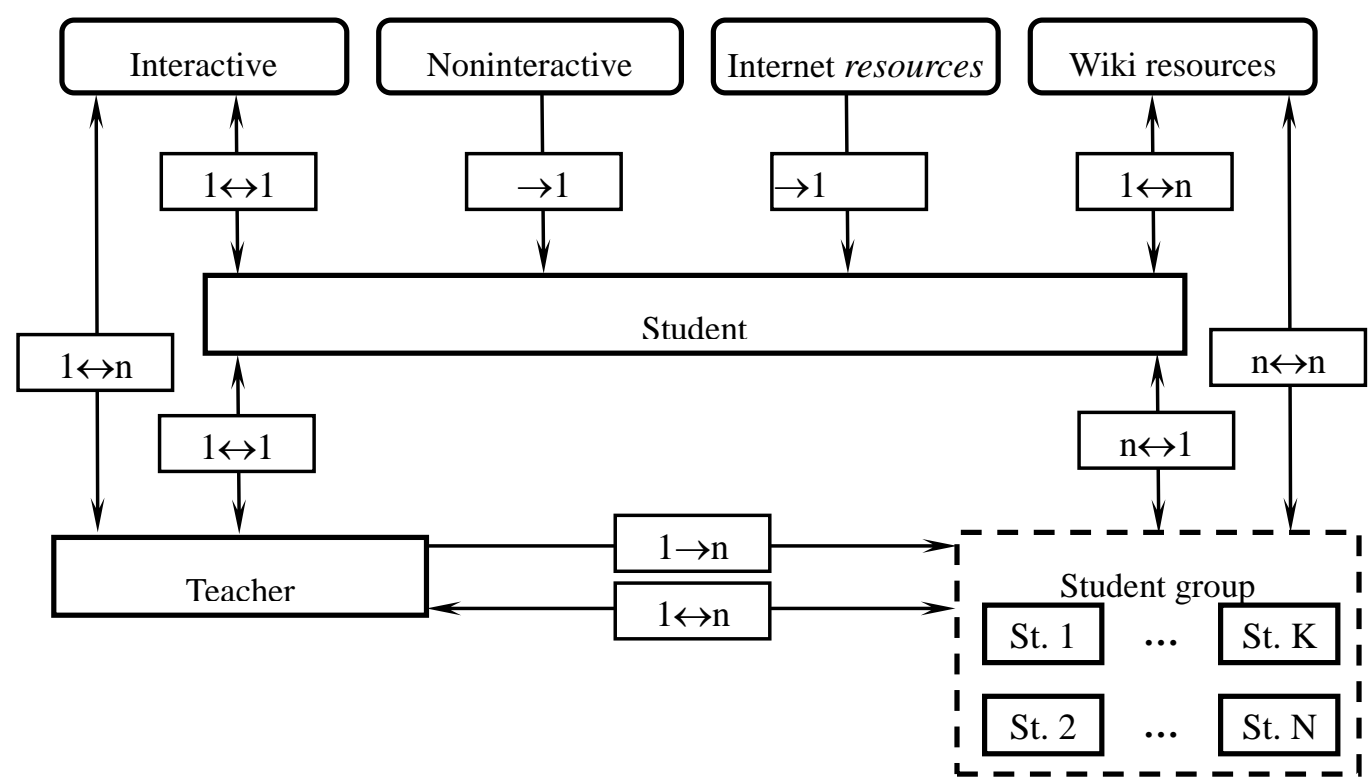

Figure 2. The model of the participants' of the educational process distant communication

\section{Information-Pedagogical Model of Teacher-Student Distant Communication}

As shown in the model in Figure 2, it is necessary to consider the general scheme of teacher-student communication. It is apparent that each student has access to all information resources and is connected with the teacher and students of the group through corresponding communication interfaces; the student also has the possibility to take part in wiki resources development. The channels providing reception of the educational information from noninteractive and Internet sources are unidirectional; channels of interaction with interactive sources (resources) are bidirectional. The teacher has the possibility to interact and manage the training process of each student through individual communication means, and groups of students through providing mass announcements and information exchange. Management is also carried out through an educational site where the teacher can place information and monitor the students' progress.

The group of students can receive the information from the teacher (Yavich \& Gerkerova, 2013); communicate with him within the frame of the general discussions (forums) or consultations. Communication of students and their teamwork over a wiki resource is also possible. The suggested model is highly generalized for several reasons. First, the model is not tied to a particular subject; hence, the information system constructed on its basis can be filled by the content on any subject. Secondly, information modules in the model structure are independent - the necessity of a reference to this or that source is determined by the teacher, depending on a solved educational problem and technological possibilities and, hence, the resulting model can be considered as the generalized scheme. It is a basis on which various concrete realizations can be constructed. Thirdly, the model is expanded concerning new information resources and communication means.

In particular, on the basis of the presented model, authors of this article have constructed and put into practice the system of distant management of students' educational activity in the course of mathematics at Ariel University (Israel), and in the course of foreign languages at South Ukrainian National Pedagogical University (Ukraine). Our experience has shown that quality content, proper use of telecommunication technologies, teachers' online working time records can start a new stage of nowadays education.

\section{Conclusion}

The constructed information-pedagogical model includes information resources, their consumers, and information streams between the participants that are realized by various technological means. A set of specified components makes it possible for a teacher to constantly manage the educational activity of the students in various academic subjects. It can be done easily and distantly. The model may help to develop the theoretical grounds for comprehensive management of students' educational activity educational activity distantly; it may be also used for the work with the students who take full-time course. 


\section{References}

Bukhanceva, N. V. (2007). Interaction in virtual space: problems and development prospects. Educational Technologies, 1, 17-22.

Hen, D. (1996). Pedagogic and technology - telecommunication application in education. Computer Science and Education, 43-49.

Ibragimov, I. M. (2005). Information of technology and means of distant education. Moscow: Publishing Centre "Academy".

Malanin, V. V., Suslonov, V. M., \& Polyanin, A. B. (2001). Information technology in educational process. University Management, 4(19), 18-21.

Mioduser, D., Nachmias, R., Lahav, O., \& Oren, A. (1999). Web-based Learning Environments: Current Pedagogical and Technological State. International Journal of Research in Computers in Education, 33(1), 55-76.

Nachmias, R. \& Segev, L. (2003). Usage of content in web-supported academic courses. Academic Exchange Quarterly, 7(1), 5-15.

Offir, B., Lev, Y., Barth, I., \& Shteinbok A. (2004). An integrated analysis of verbal and nonverbal interaction in conventional and distance learning environments. Journal of Educational Computing Research, 31(2), 101-118. https://doi.org/10.2190/tm7u-qrf1-0eg7-p9p7

Prozorov, O. A. (2003). The organisation of the environment of educational information interaction on the basis of the Internet. Computer Science and Education, 3, 62-66.

Starichenko, B. E., Davidovich, N., Yavich, R., \& Mahrova, L. V. (2007). Management of educational activity of students on the basis of network information technologies. Science and Education, 6, 3-15.

Roman Yavich, Social networks and students. Research Journal of Management Sciences, 2(2), 1-2, February (2013), $1-3$.

Nitza Davidovich, Roman Yavich \& Alexander Domoshnitsky. (2012). Mathematical Games: International Mathematics Olympiad for Students. Far East Journal of Mathematical Education, 9(2), 133-140. http://www.pphmj.com/abstract/7116.htm

Domoshnitsky Alexander \& Roman Yavich. (2009). Mathematical Competitions for University Students,Proceedings of the 10th International Conference Models in Developing Mathematics Education, Dresden, Saxony,Germany, 143-145. urn:nbn:de:bsz:14-qucosa-79653

Domoshnitsky, Alexander, \& Roman Yavich. (2009). Internet Mathematical Olympiads. Proceedings of the 10th International Conference Models in Developing Mathematics Education, Dresden, Saxony, Germany. 2009. urn:nbn:de:bsz:14-qucosa-79663

Davidovich Nitza \& Roman Yavich. (2013). Course Websites and their Contribution to Students Evaluation of Instructors and their Courses. Research Journal of Management Sciences, 2(3), 1-7.

Starichenko, Boris E., Artem N. Egorov, \& Roman Yavich. (2013). Feautures of Application of Classroom Response System at the Lectures in Russia and Israel. International Journal of Higher Education, 2(3), 23. https://doi.org/10.5430/ijhe.v2n3p23

Yavich, Roman, \& Alexandra Gerkerova. (2013). Teaching Methods and Assessment. American Journal of Educational Research, 1(7), 260-262. https://doi.org/10.12691/education-1-7-7 